\title{
A Flow-Batch Analyzer for UV-Vis Spectrophotometric Detection of Adulteration in Distilled Spirits
}

\author{
Elaine C. L. Nascimento, ${ }^{a}$ Mário C. U. Araújo*,b and Roberto K. H. Galvão ${ }^{c}$ \\ ${ }^{a}$ Unidade Acadêmica de Serra Talhada, Universidade Federal Rural de Pernambuco, \\ 52171-900 Serra Talhada-PE, Brazil \\ ${ }^{b}$ Departamento de Química, Universidade Federal da Paraíba, CCEN, CP 5093, \\ 58051-970 João Pessoa-PB, Brazil \\ 'Divisão de Engenharia Eletrônica, Instituto Tecnológico de Aeronáutica, \\ 12228-900 São José dos Campos-SP, Brazil
}

\begin{abstract}
Um analisador flow-batch é proposto para detecção de adulterações em bebidas destiladas (uísque, conhaque, cachaça, rum e vodca) usando espectrofotometria UV-Vis. O analisador foi empregado para diluir as amostras não-adulteradas e para simular adulterações com adição de 5 e $10 \%(\mathrm{v} / \mathrm{v})$ de água, etanol ou metanol. Modelos de classificação SIMCA (soft independent modelling of class analogies) foram construídos empregando espectros de amostras adulteradas e não-adulteradas na faixa de 235-355 nm. Aplicando-se os modelos SIMCA a um conjunto de teste, todas as amostras adulteradas e não-adulteradas foram corretamente discriminadas com um nível de confiança de $95 \%$ e uma frequência analítica superior a 120 amostras por hora.
\end{abstract}

An automatic flow-batch analyzer is proposed for detection of adulteration in distilled spirits (whiskey, brandy, cachaça, rum and vodka) using UV-Vis spectrophotometry. The analyzer was employed to dilute the non-adulterated samples and to simulate adulteration with addition of 5 and $10 \%(\mathrm{v} / \mathrm{v})$ of water, ethanol or methanol. SIMCA (soft independent modelling of class analogies) classification models were built using spectra of non-adulterated and adulterated samples in the region of 235-355 $\mathrm{nm}$. By applying the SIMCA models to a test set, all adulterated and non-adulterated samples were correctly discriminated at a confidence level of $95 \%$ with an analytical throughput larger than 120 samples per hour.

Keywords: flow-batch analyzer, SIMCA, UV-Vis spectrophotometry, adulteration of distilled spirits, screening analysis

\section{Introduction}

The adulteration of distilled spirits with water, ethanol or methanol is a problem with serious repercussions, which compromises the product quality, leads to loss of tax revenue and may constitute a public health threat. ${ }^{1-5}$ In a study concerning the chemical composition of 608 beverage samples retailed in Brazil over the period 1993-1999, 391 samples were found to be out of quality standards. ${ }^{5}$ In two cases, the methanol levels were above the tolerance limit stated in Brazilian legislation. In that study, the analyses were carried out by chromatography in gaseous phase with a flame ionization detector.

*e-mail: laqa@quimica.ufpb.br
Chromatography is a powerful analytical method, which has been used in several works to detect adulteration in distilled spirits. ${ }^{6-8}$ However, such method presents some disadvantages, including high cost of the instrumentation, low analytical throughput, high consumption of reagents and samples and generation of harmful residues. ${ }^{5,9}$ These limitations have motivated the development of spectrophotometric techniques for screening analysis ${ }^{10-19}$ with the aim of reducing the number of samples that need to be analyzed by chromatographic methods. In this context, chemometrics plays a key role in the achievement of good screening results. ${ }^{10-12}$

A previous work ${ }^{10}$ proposed the use of near-infrared spectroscopy (NIR) and chemometrics to classify 69 samples of distilled spirits with respect to type (whiskey, 
brandy, rum and vodka) and presence/absence of adulterants. Classification was accomplished by using the SIMCA (soft independent modelling of class analogies) technique. The proposed method successfully discriminated pure samples from those with adulteration (100\% of correct prediction at a confidence level of 95\%). However, that work still entailed a high cost of instrumentation.

An alternative to NIR spectroscopic methods would be the use of UV-Vis spectrophotometry, which involves a simpler and cheaper instrumentation. Barbosa-García et al. ${ }^{20}$ employed UV-Vis spectrophotometry and principal component analysis (PCA) to discriminate among different brands of tequila. Moreover, partial-least-squares discriminant analysis (PLS-DA) was employed to separate pure agave tequila from mixed samples. MacKenzie and Aylott ${ }^{21}$ devised a method to authenticate whiskey on the basis of 10 wavelengths suitably chosen in the range $230-500 \mathrm{~nm}$ for a laboratory spectrophotometer and 220-360 $\mathrm{nm}$ for a field instrument. The authors suggested that the UV-Vis spectrophotometric method has the potential to be used for authenticating other types of distilled spirits.

These two works indicated that UV-Vis spectrophotometry is a viable technique for discrimination and authentication of alcoholic beverages. However, they still entailed the manual handling of samples in the spectral measurements. To circumvent this drawback, flow-batch analyzers (FBAs), which were proposed and first described by Honorato and co-workers, ${ }^{22}$ constitute a good alternative. FBAs are automatic systems that draw upon the useful features of flow, batch and multi-commutation approaches. Such hybridization retains the reliability of classical batch mode methods with a modern, fully computer-controlled and miniaturized mixing assembly accessory, exchanging the use of large amounts of solutions for micro-volumes, typically employed in conventional flow systems.

FBAs differ from conventional flow approaches in that a carrier is not employed to transport the sample to the detector. Therefore, the flow reaching the detector does not have concentration gradients (i.e. there is no sample zone in the flow), which facilitates the measurement process. Moreover, the selection of washing time, flow rates, tubing diameters and lengths is not a critical factor.

Generically, a dilution/mixing/reaction chamber, containing a magnetic stirring bar, is inserted in a FBA to allow all the chemicals to be thoroughly mixed, as in classical batch analysis methods, before flowing to the detector for monitoring the analytical signal. As a result, efficient mixing and dilution of reagents, sample and any other solutions in a $\mu \mathrm{L}$ volume range can be easily controlled by software.
While most flow analysis systems usually require a specific apparatus assembly for each particular method, strongly limiting their widespread acceptance in routine analysis laboratories, a flow-batch system can be viewed as a universal purpose accessory tool easily attached to any conventional equipment for instrumental analysis. However, the main advantage of the flow-batch analyzer is that classical methods can be updated for better precision and speed. Probably, the most outstanding characteristic of a flow-batch approach is the opportunity offered for developing analytical methods by software (multi-task characteristic). Moreover, as most flow analyzers, FBA also presents good precision and accuracy, as well as high sample throughput and low consumption and manipulation of reagents and samples. Such features result in lower cost per analysis, reduced production of waste chemicals and fewer chances of human error.

Versatile and flexible flow-batch analyzers have been proposed to automate several analytical processes, ${ }^{17,22-41}$ such as hardness screening of water, ${ }^{17}$ titrations, ${ }^{22-26}$ analyte ${ }^{27-30}$ and internal standard additions, ${ }^{31}$ preparation of calibration solutions for uni ${ }^{32}$ and multivariate ${ }^{33}$ calibration, in line matching of $\mathrm{pH}^{34}$ salinity ${ }^{35}$ and acidity ${ }^{36}$ between standard solutions and samples, prior assays ${ }^{23}$ exploitation of concentration gradients, ${ }^{24,37}$ use of kinetics for nonlinear ${ }^{37}$ and multivariate calibrations, ${ }^{38}$ chemiluminescence ${ }^{39}$ and nephelometric ${ }^{40}$ analyses, in line coulometric generation of the standards or titrants ${ }^{26,28,29}$ and extraction procedures. ${ }^{41}$

In the present work, a FBA is employed to develop an automatic UV-Vis spectrophotometric screening analysis method for detection of adulteration in distilled spirits (whiskey, brandy, cachaça, rum and vodka). Adulteration with water, ethanol or methanol at 5 and $10 \%$ (v/v) levels are considered, as in a previous work..$^{10}$ Although these adulterants have no absorption in the UV-Vis spectral range, it is not possible to rule out the presence of analyte/solvent interactions in addition to the dilution effects. For this reason, a multivariate data treatment procedure is adopted. More specifically, SIMCA classification models are employed to discriminate the UV-Vis spectra of adulterated samples from non-adulterated ones.

\section{Experimental}

\section{Samples and adulterants}

This work involved 60 alcoholic beverage samples of five types, namely whiskey, brandy, cachaça, rum and vodka (12 samples of each type), which were acquired from supermarkets in João Pessoa (PB, Brazil). The 12 samples 
for each beverage type were of the same brand, but with different lot numbers.

For each beverage type, six adulteration cases of the same sample were simulated by addition of 5 or $10 \%$ $(\mathrm{v} / \mathrm{v})$ of water, ethanol or methanol. Water was distilled and deionized by using a Milli-Q Plus system (Millipore, Billerica, MA, USA). Ethanol and methanol were of analytical degree (Merck, P.A.). In addition, five samples provided by a reference laboratory were employed: two of whiskey $\left(\mathrm{W}_{\mathrm{rl}}\right)$, one of brandy $\left(\mathrm{B}_{\mathrm{rl}}\right)$ and two of rum $\left(\mathrm{R}_{\mathrm{rl}}\right)$. These samples had been previously analyzed by chromatography in gaseous phase with a flame ionization detector. As a result, the whiskey and rum samples were found to be adulterated, whereas the brandy sample was not.

As some alcoholic beverages presented strong absorption in the UV-Vis spectral region, prior to spectral acquisition these samples were diluted with water in the following ratios (v/v): 1:6 (whiskey), 1:10 (brandy) and 1:2 (cachaça). Dilution of rum and vodka samples was not needed, as they presented low absorption in the spectral region under consideration.

\section{Apparatus}

Figure 1(a) shows the automatic flow-batch analyzer designed for use in this work. It comprises four three-

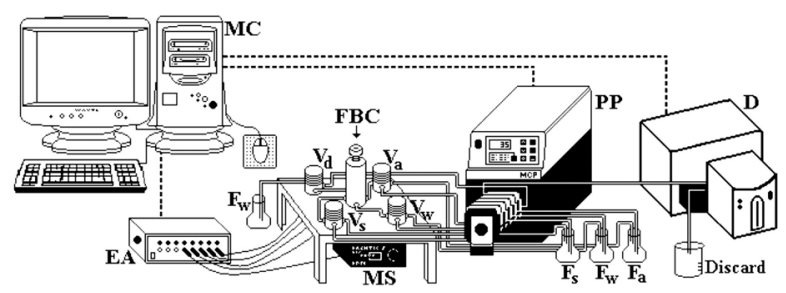

(a)

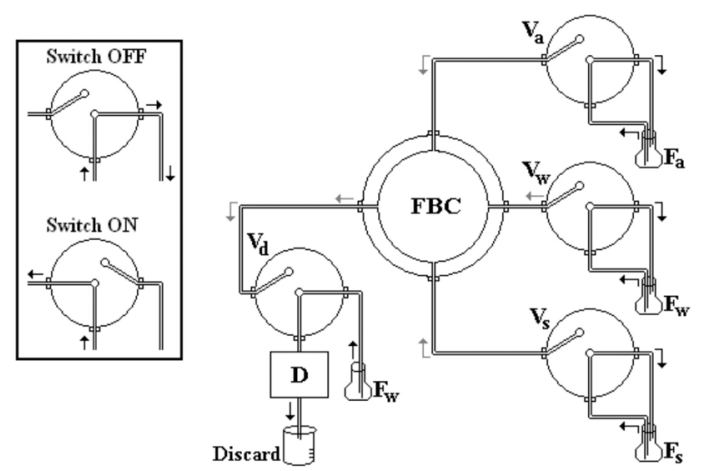

(b)

Figure 1. (a) Diagram of the flow-batch analyzer: $E A=$ electronic actuator, $\mathrm{FBC}=$ flow-batch chamber, $\mathrm{MS}=$ magnetic stirrer, $\mathrm{PP}=$ peristaltic pump, $\mathrm{V}_{\mathrm{s}}, \mathrm{V}_{\mathrm{w}}, \mathrm{V}_{\mathrm{a}}, \mathrm{V}_{\mathrm{d}}$ = solenoid valves of sample, water, adulterant and detector, respectively, $\mathrm{F}_{\mathrm{s}}, \mathrm{F}_{\mathrm{w}}, \mathrm{F}_{\mathrm{a}}=$ flask of sample, water and adulterant, respectively, $\mathrm{MC}=$ microcomputer and $\mathrm{D}=\mathrm{UV}$-Vis spectrophotometer. (b) Simplified diagram of flow-batch analyzer and the configurations of valves (ON and $\mathrm{OFF}$ ). way solenoid valves (Cole-Parmer, Vernon Hills, Illinois, USA), a lab-made valve driver, a peristaltic pump (Gilson Miniplus $^{\circledR}$ 3, Villiers Le Bel, Paris, France), a flow-batch chamber consisting of a PTFE (polytetrafluoroethylene) cylinder (Teflon $®)$ with a magnetic bar in its interior, a magnetic stirrer (IKA ${ }^{\circledR}$ - Staufen, Breisgau, Germany, model 8068) and a quartz flow cell (HELLMA ${ }^{\circledR}$ - Müllheim, Breisgau, Germany) with an optical path of $1.0 \mathrm{~cm}$. The UV-Vis spectra are acquired by using a HewlettPackard 8453 spectrophotometer with photodiode array. A microcomputer is employed for data acquisition and control of the flow-batch analyzer with software developed in the LabView ${ }^{\circledR}$ 5.1-National Instruments, Austin, Texas, USA, platform. An electronic actuator is used to drive the magnetic stirrer and valves. Figure 1(b) presents a simplified diagram of the flow-batch analyzer with the two possible valve configurations (ON and OFF).

\section{Procedure}

Initially, all the valves are switched OFF and the feeding sample, water and adulterant are continuously pumped back to their flasks, while the spectrophotometric flow-cell is kept under wash with water. The $\mathrm{V}_{\mathrm{s}}, \mathrm{V}_{\mathrm{w}}$ and $\mathrm{V}_{\mathrm{a}}$ valves are then simultaneously switched $\mathrm{ON}$ and the solutions are pumped to fill the channels between the valves and FBC. After $2 \mathrm{~s}$, the $\mathrm{V}_{\mathrm{d}}$ valve is switched ON. Then, the content of FBC is aspirated to waste (discard flask) during $3 \mathrm{~s}$. This process is repeated whenever the solution in each channel is changed. The timing employed for dilution, adulteration and spectral measurement of the samples is indicated in cases 1 to 8 in Table 1 .

Cases 1 and 2 describe the valve timing sequence for measurement of non-adulterated samples. In case 1, for example, the whiskey sample was diluted by switching ON the $\mathrm{V}_{\mathrm{s}}$ and $\mathrm{V}_{\mathrm{w}}$ valves (Figure 1) during $\mathrm{t}_{\mathrm{s}}=1.0 \mathrm{~s}$ and $\mathrm{t}_{\mathrm{w}}=6.0 \mathrm{~s}$, respectively. The $\mathrm{V}_{\mathrm{d}}$ valve was then switched $\mathrm{ON}$ during $\mathrm{t}_{\mathrm{d} 1}=7.0 \mathrm{~s}$ and the sample spectrum was recorded. These operations were repeated six times in order to obtain six whiskey spectra. A similar procedure was employed to obtain the spectra of brandy and cachaça. In case 2, the rum and vodka spectra were recorded without the need for sample dilution.

Cases 3-6 concern the measurement of samples with 5 (cases 3 and 4) and 10\% (cases 5 and 6) (v/v) of adulterant. In case 3, for example, the whiskey sample was initially diluted by switching $\mathrm{ON}$ the $\mathrm{V}_{\mathrm{s}}$ and $\mathrm{V}_{\mathrm{w}}$ valves during $\mathrm{t}_{\mathrm{s}}=3.0 \mathrm{~s}$ and $\mathrm{t}_{\mathrm{w}}=18.0 \mathrm{~s}$, respectively. The $\mathrm{V}_{\mathrm{d}}$ valve was then switched ON during $t_{d 1}=11.5 \mathrm{~s}$ in order to record an additional spectrum of non-adulterated whiskey. Adulteration at $5 \%(\mathrm{v} / \mathrm{v})$ was performed by switching 
Table 1. Valve timing sequences (in seconds) for dilution, adulteration and spectral measurement of the samples. The $t_{s}$, $t_{w}$ and $t_{a}$ time intervals indicate the time during which $V_{s}, V_{w}$ and $V_{a}$ valves remain switched $O N$, whereas $t_{d 1}, t_{d 2}$ refer to valve $V_{d}$

\begin{tabular}{|c|c|c|c|c|c|c|c|}
\hline \multirow[t]{2}{*}{ Case } & \multirow[t]{2}{*}{ Sample } & \multirow{2}{*}{$\begin{array}{l}\text { Dilution ratio } \\
(\mathrm{v} / \mathrm{v})\end{array}$} & \multicolumn{2}{|c|}{ Dilution } & \multirow{2}{*}{$\frac{\text { Measurement }}{\mathrm{t}_{\mathrm{d} 1}}$} & \multirow{2}{*}{$\frac{\text { Adulteration }}{\mathrm{t}_{\mathrm{a}}}$} & \multirow{2}{*}{$\frac{\text { Measurement }}{\mathrm{t}_{\mathrm{d} 2}}$} \\
\hline & & & $\mathrm{t}_{\mathrm{s}}$ & $\mathrm{t}_{\mathrm{w}}$ & & & \\
\hline \multirow[t]{3}{*}{1} & whiskey & $1: 6$ & 1.0 & 6.0 & 7.0 & - & - \\
\hline & brandy & $1: 10$ & 1.0 & 10.0 & 11.0 & - & - \\
\hline & cachaça & $1: 2$ & 3.0 & 6.0 & 9.0 & - & - \\
\hline \multirow[t]{2}{*}{2} & rum & - & 7.0 & - & 7.0 & - & - \\
\hline & vodka & - & 7.0 & - & 7.0 & - & - \\
\hline \multirow[t]{3}{*}{3} & whiskey & $1: 6$ & 3.0 & 18.0 & 11.5 & 0.5 & 10.0 \\
\hline & brandy & $1: 10$ & 2.0 & 20.0 & 12.5 & 0.5 & 10.0 \\
\hline & cachaça & $1: 2$ & 7.0 & 14.0 & 11.5 & 0.5 & 10.0 \\
\hline \multirow[t]{2}{*}{4} & rum & - & 17.0 & - & 7.5 & 0.5 & 10.0 \\
\hline & vodka & - & 17.0 & - & 7.5 & 0.5 & 10.0 \\
\hline \multirow[t]{3}{*}{5} & whiskey & $1: 6$ & 3.0 & 18.0 & 12.0 & 1.0 & 10.0 \\
\hline & brandy & $1: 10$ & 2.0 & 20.0 & 13.0 & 1.0 & 10.0 \\
\hline & cachaça & $1: 2$ & 7.0 & 14.0 & 12.0 & 1.0 & 10.0 \\
\hline \multirow[t]{2}{*}{6} & rum & - & 17.0 & - & 8.0 & 1.0 & 10.0 \\
\hline & vodka & - & 17.0 & - & 8.0 & 1.0 & 10.0 \\
\hline \multirow[t]{2}{*}{7} & $\mathrm{~W}_{\mathrm{rl}}$ & $1: 6$ & 1.0 & 6.0 & 7.0 & - & - \\
\hline & $\mathrm{B}_{\mathrm{rl}}$ & $1: 10$ & 1.0 & 10.0 & 11.0 & - & - \\
\hline 8 & $\mathrm{R}_{\mathrm{rl}}$ & - & 7.0 & - & 7.0 & - & - \\
\hline
\end{tabular}

ON the $\mathrm{V}_{\mathrm{a}}$ valve during $\mathrm{t}_{\mathrm{a}}=0.5 \mathrm{~s}$. Finally, the $\mathrm{V}_{\mathrm{d}}$ valve was switched ON during $\mathrm{t}_{\mathrm{d} 2}=10.0 \mathrm{~s}$ and the adulterated whiskey spectrum was recorded. For adulteration with $10 \%(\mathrm{v} / \mathrm{v})$, the $\mathrm{t}_{\mathrm{d} 1}$ and $\mathrm{t}_{\mathrm{a}}$ times were changed to $12.0 \mathrm{~s}$ and $1.0 \mathrm{~s}$, respectively (case 5). These operations were carried out for adulteration with water, ethanol and methanol by changing the $\mathrm{F}_{\mathrm{a}}$ flask (Figure 1) accordingly. As a result, a total of 12 whiskey spectra were recorded in cases 3 and 5 (six of the non-adulterated sample, three with the sample adulterated at $5 \% \mathrm{v} / \mathrm{v}$ and three with the sample adulterated at $10 \% \mathrm{v} / \mathrm{v})$. A similar procedure was employed with the other beverage types.

Finally, in cases 7 and 8, a spectrum was recorded for each of the five samples (two of $\mathrm{W}_{\mathrm{rl}}$, one of $\mathrm{B}_{\mathrm{rl}}$ and two of $\mathrm{R}_{\mathrm{rl}}$ ) provided by the reference laboratory.

Before the measurement of each sample spectrum, the FBC content was homogenized during $3.0 \mathrm{~s}$ by using the magnetically-driven stirrer bar.

\section{Software}

PCA and SIMCA calculations were carried out by using the software package The Unscrambler 9.7-CAMO Software AS, Nedre Vollgate, Oslo, Norway. The default confidence level for SIMCA classification (95\%) was adopted and the number of principal components for each SIMCA model was chosen on the basis of explained variance plots.
The experimental procedure resulted in a total of 95 spectra (60 of non-adulterated samples, 30 of adulterated samples and 5 of the samples provided by the reference laboratory). A SIMCA model was built for each beverage type by using 10 spectra of non-adulterated samples. The remaining spectra were employed as a test set for the discrimination of adulterated samples from non-adulterated ones.

\section{Results and discussion}

\section{Optimization of flow-batch procedure and parameters}

The optimization of flow-batch procedure and parameters, such as the volumes added into FBC, flowrates, and the timing employed for dilution, adulteration and spectral measurement of the samples was performed by using a univariate method. A compromise was sought among low sample and adulterant consumption, high sample throughput, good sensitivity and reproducibility of the spectral measurements.

As v $=\mathrm{Q} t$ (where $\mathrm{Q}$ is the channel flow-rate), the valve timing courses, $t$, define the volumes, $v$, added into FBC. Since the total volume of $\mathrm{FBC}$ is $2.0 \mathrm{~mL}$, a flow-rate of $3.0 \mathrm{~mL} \mathrm{~min}^{-1}$ was selected for sample, water and adulterant channels (Figure 1). The optimized timing employed for dilution, adulteration and spectral measurement of the samples is indicated in Table 1. 
It is worth noting that the errors associated with valve activation depend on its minimum response time (about $20 \mathrm{~ms}$ according to the valve manufacturer data) and the errors inherent to computational processing. The uncertainties from fluid delivery by the solenoid valves were assessed by using a $3.0 \mathrm{~mL} \mathrm{~min}^{-1}$ flow-rate for each channel. Water was delivered into weighing bottles at time intervals of 0.5-20 s and their masses were measured by an analytical balance. The relative standard deviations for 10 replicate measurements in each time interval were always $<1.0 \%$.

Owing to the hydrophobic characteristic of the PTFE materials used in the FBC, valves and transmission lines of the flow-batch manifold, a cleaning step was found to be unnecessary in the present work. This conclusion was achieved by delivering the samples into the FBC during 23 s, emptying the FBC content through the UV-Vis spectrophotometer and then repeating this procedure with water. As a result, no change in the blank signal (carryover) was detected in the spectrophotometer. However, carryover may occur in other applications if organic species in the sample matrix adhere to the surface of the PTFE materials. In that case, a cleaning step can be performed by switching $\mathrm{ON}$ the $\mathrm{V}_{\mathrm{w}}$ valve during $23 \mathrm{~s}$, homogenizing the content in $\mathrm{FBC}$ during $3.0 \mathrm{~s}$ and then switching $\mathrm{ON}$ the $\mathrm{V}_{\mathrm{d}}$ valve during $25 \mathrm{~s}$ in order to empty FBC and the channel between FBC and spectrophotometer. This procedure should be repeated (one, two or three times) until the baseline signal is restored.

\section{Preliminary analysis of the sample spectra}

Figure 2 shows the average UV spectra of each nonadulterated beverage type in the range from 200 to $400 \mathrm{~nm}$. As it can be seen, the absorbance values in the range

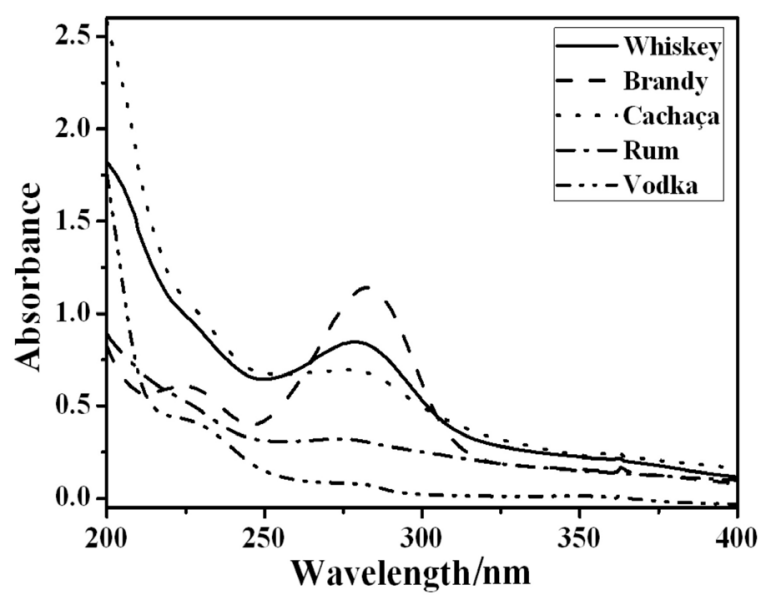

Figure 2. Average UV spectra of each non-adulterated beverage type in the range from 200 to $400 \mathrm{~nm}$. below $235 \mathrm{~nm}$ are too large (close to saturation) while the non-adulterated beverages do not present relevant spectral information in the region above $355 \mathrm{~nm}$. Therefore, the spectral range between $235-355 \mathrm{~nm}$ was chosen to build the chemometric models. Such range is similar to that employed by MacKenzie and Aylott ${ }^{21}$ in their field instrument (220-350 nm) for authentication of whiskey samples.

Figure 3 presents the PC1 $\times$ PC2 score plot for the calibration set, which consists of 50 non-adulterated samples. The five beverage types are clearly separated in the PC1 $\times$ PC2 space, which shows that the chosen spectral range conveys appropriate discriminatory information.

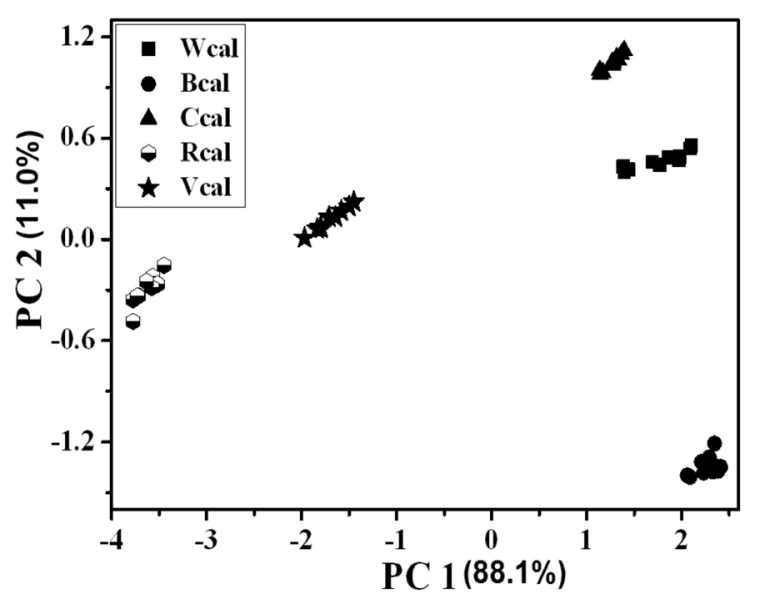

Figure 3. PC1 vs. PC2 score plot for the calibration set. PC1 and PC2 explain 88.1 and $11.0 \%$ of the variance, respectively. The whiskey, brandy, cachaça, rum and vodka samples are denoted by $\mathrm{W}_{\text {cal }}, \mathrm{B}_{\text {cal }}, \mathrm{C}_{\text {cal }}, \mathrm{R}_{\text {cal }}$ and $\mathrm{V}_{\text {cal }}$, respectively.

\section{Classification results}

Following the procedure described above, five SIMCA models were obtained: whiskey (2 PCs), brandy (2 PCs), cachaça (3 PCs), rum (2 PCs) and vodka (4 PCs). These models were applied to the test set, which consisted of two non-adulterated samples of each beverage type, six samples of each beverage type adulterated by using the flow-batch analyzer and five samples provided by the reference laboratory (two of adulterated whiskey, one of non-adulterated brandy and two of adulterated rum). The classification results were in agreement with the expected outcome in that: $(i)$ all non-adulterated samples were correctly assigned to their corresponding classes (i.e. no false alarms would be issued in the screening process) and (ii) the adulterated samples were not included in any of the classes (i.e. all adulteration would be correctly detected in the screening process).

For illustration, Figure 4 shows the projection of the whiskey samples in the $\mathrm{PC} 1 \times \mathrm{PC} 2 \times \mathrm{PC} 3$ space. As it can 


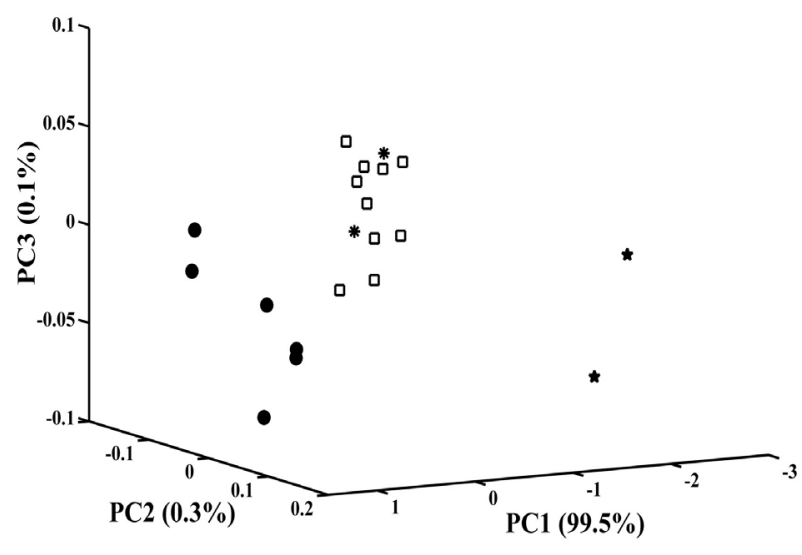

Figure 4. Projection of the whiskey samples in the $\mathrm{PC} 1 \times \mathrm{PC} 2 \times \mathrm{PC} 3$ space. The explained variance of PC1, PC2 and PC3 were 99.5, 0.3 and $0.1 \%$, respectively. $\square=\mathrm{W}_{\text {cal }}, *=\mathrm{W}_{\text {non-adult }} \bullet=\mathrm{W}_{\text {adult }}$ and $\star=\mathrm{W}_{\mathrm{rl}}$.

be seen, the two non-adulterated test samples ( $\left.\mathrm{W}_{\text {non-adult }}\right)$ fall in the same region of the calibration samples $\left(\mathrm{W}_{\text {cal }}\right)$. In contrast, the samples adulterated with water, ethanol and methanol $\left(\mathrm{W}_{\text {adult }}\right)$ are clearly separated from the nonadulterated samples. The two samples provided by the reference laboratory $\left(\mathrm{W}_{\mathrm{rl}}\right)$ would also be classified as not belonging to the non-adulterated whiskey type. However, they are not located in the same cluster of the synthetically adulterated samples, which suggests that $\mathrm{W}_{\mathrm{rl}}$ samples may contain adulterants other than water, ethanol or methanol. Although not shown in Figure 4, the non-adulterated and adulterated samples of brandy, cachaça, rum and vodka are also located outside the region of non-adulterated whiskey samples.

Figure 5 shows the projection of the brandy samples in the $\mathrm{PC} 1 \times \mathrm{PC} 2 \times \mathrm{PC} 3$ space. As it can be seen, the nonadulterated test sample provided by the reference laboratory $\left(\mathrm{B}_{\mathrm{r} 1}\right)$ is close to the non-adulterated samples used in the construction of the model. This finding corroborates the SIMCA result, which assigned sample $\mathrm{B}_{\mathrm{rl}}$ to the class of non-adulterated brandy samples.

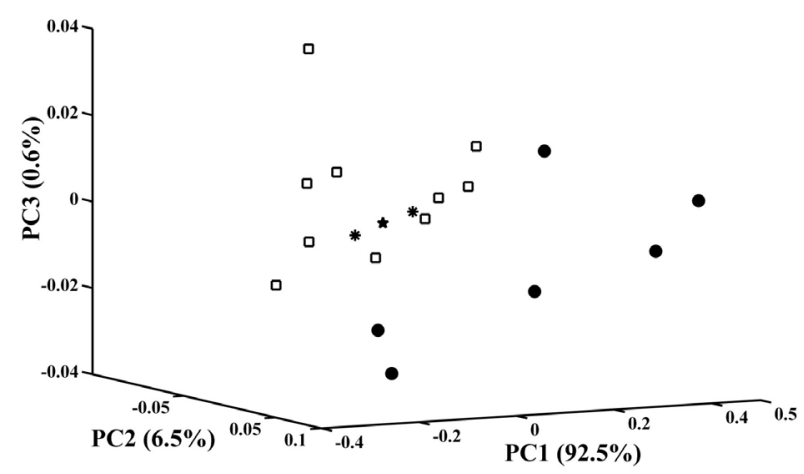

Figure 5. Projection of the brandy samples in the $\mathrm{PC} 1 \times \mathrm{PC} 2 \times \mathrm{PC} 3$ space. The explained variance of $\mathrm{PC} 1, \mathrm{PC} 2$ and $\mathrm{PC} 3$ were $92.5,6.5$ and $0.6 \%$, respectively. $\square=\mathrm{B}_{\text {cal }}, *=\mathrm{B}_{\text {test }}, \bullet=\mathrm{B}_{\text {adult }}$ and $\star=\mathrm{B}_{\mathrm{rl}}$.

\section{Conclusions}

This paper presented a simple method for screening analysis of distilled spirits with respect to the presence of adulteration. More specifically, adulteration with water, ethanol and methanol at 5 and $10 \%(\mathrm{v} / \mathrm{v})$ were considered. The main contributions with respect to a previous work ${ }^{10}$ consisted of the use of a simpler instrumentation (UV-Vis spectrophotometer), as well as the automation of the sample handling process through the use of a flow-batch analyzer with high analytical throughput (> 120 samples per hour). The SIMCA classification models were able to detect all adulterated samples, including those provided by a reference laboratory. The spectrophotometric approach adopted in the proposed method has the advantage of taking into account possible analyte/solvent interactions, in addition to dilution effects. Moreover, the analyst is not required to know the beverage type (whiskey, brandy, cachaça, rum or vodka) a priori, as such information is automatically determined by the classification models.

It is worth noting that the FBA parameters can be easily modified to adapt the proposed approach to the screening analysis of other alcoholic beverages. For this purpose, different experimental designs can be programmed in a rapid, flexible, versatile manner simply by changing time configurations in the graphic user interface of the FBA software. If the expected analyte concentration varies within a larger range, for example, the dilution of the samples can be altered via software without the need for physical modifications in the FBA manifold. Therefore, downtime can be minimized in large scale routine analyses.

\section{Acknowledgements}

The authors thank the Brazilian Agencies: Conselho Nacional de Desenvolvimento Científico e Tecnológico $(\mathrm{CNPq})$ for research fellowships and Coordenação de Aperfeiçoamento de Pessoal de Nível Superior (CAPES) for scholarship.

\section{References}

1. Binder, F.; Voges, E.; Lauge, P.; Food Addit. Contam., Part A 1988, 5, 343 .

2. Moubarik, A.; Benkirane, R.; Soulaymani, R.; Toxicol. Lett. 1998, 95, 71 .

3. Darwish, A.; Roth, C. E.; Duclos, P.; Ohn, S. A.; Nassar, A.; Mahoney, F.; Vogt, R.; Arthur, R. R.; Vaccine 2002, 20, 3585.

4. Costa, R. S.; Santos, S. R. B.; Almeida, L. F.; Nascimento, E. C. L.; Pontes, M. J. C.; Lima, R. A. C.; Simões, S. S.; Araújo, M. C. U.; Microchem. J. 2004, 78, 27. 
5. Nagato, L. A. F.; Duran, M. C.; Caruso, M. S. F.; Barsotti, R. C. F.; Badolato, E. S. G.; Ciênc. Tecnol. Aliment. 2001, 21, 39.

6. Winterova, R.; Mikulikova, R.; Mazac, J.; Havelec, P.; Czech J. Food Sci. 2008, 26, 368.

7. Lachenmeier, D. W.; Attig, R.; Frank, W.; Athanasakis, C.; Eur. Food Res. Tech. 2003, 218, 105.

8. Bauer-Christoph, C.; Wachter, H.; Christoph, N.; Rossmann, A.; Adam, L.; Z. Lebensm. Unters. Forsch. A 1997, 204, 445.

9. Arvanitoyannis, I. S.; Katsota, M. N.; Psarra, E. P.; Soufleros, E. H.; Kallithraka, S.; Trends Food Sci. Technol. 1999, 10, 321.

10. Pontes, M. J. C.; Santos, S. R. B.; Araújo, M. C. U.; Almeida, L. F.; Lima, R. A. C.; Gaião, E. N.; Souto, U. T. C. P.; Food Res. Int. 2006, 39, 182.

11. Palma, M.; Barroso, C. G.; Talanta 2002, 58, 265.

12. Barboza, F. D.; Poppi, R. J.; Anal. Bioanal. Chem. 2003, 377, 695.

13. Medeiros, V. M.; Araujo, M. C. U.; Galvão, R. K. H.; Silva, E. C.; Saldanha, T. C. B.; Toscano, I. A. S.; Oliveira, M. S. R.; Freitas, S. K. B.; Mariano Neto, M.; Water Res. 2005, 39, 3089.

14. Pulido, A.; Ruisánchez, I.; Bóque, R.; Rius, F. X.; Trends Anal. Chem. 2003, 22, 647.

15. Valcarcel, M.; Cardenas, S.; Gallego, M.; Trends Anal. Chem. 1999, 18, 685.

16. Gaião, E. N.; Santos, S. R. B.; Santos, V. B.; Nascimento, E. C. L.; Lima, R. S.; Araújo, M. C. U.; Talanta 2008, 75, 792.

17. Lima, R. A. C.; Santos, S. R. B.; Costa, R. S.; Marcone, G. P. S.; Honorato, R. S.; Nascimento, V. B.; Araújo, M. C. U.; Anal. Chim. Acta 2004, 518, 25.

18. Lachenmeier, D. W.; Richling, E.; López, M. G.; Frank, W.; Schreier, P.; J. Agric. Food Chem. 2005, 53, 2151.

19. Lachenmeier, D. W.; Food Chem. 2007, 101, 825.

20. Barbosa-García, O.; Ramos-Ortíz, G.; Maldonado, J. L.; Pichardo-Molina, J. L.; Meneses-Nava, M. A.; Landgrave, J. E. A.; Cervantes-Martínez., J.; Spectrochim. Acta A 2007, 66, 129.

21. MacKenzie, W. M.; Aylott, R. I.; Analyst 2004, 129, 607.

22. Honorato, R. S.; Araújo, M. C. U.; Lima, R. A. C.; Zagatto, E. A. G.; Lapa, R. A. S.; Lima, J. L. F. C.; Anal. Chim. Acta 1999, 396, 91.

23. Honorato, R. S.; Zagatto, E. A. G.; Lima, R. A. C.; Araújo, M. C. U.; Anal. Chim. Acta 2000, 416, 231.

24. Medeiros, E. P.; Nascimento, E. C. L.; Medeiros, A. C. D.; Veras Neto, J. G.; Silva, E. C.; Araújo, M. C. U.; Anal. Chim. Acta 2004, 511, 113.
25. Garcia, A. J. C.; Reis, B. F.; J. Autom. Methods Manag. Chem. 2006, Article ID83247, DOI 10.1155/JAMMC/2006/83247.

26. Pasquini, C.; Aquino, E. V.; Rebouças, M. V.; Gonzaga, F. B.; Anal. Chim. Acta 2007, 600, 84.

27. Almeida, L. F.; Martins, V. L.; Silva, E. C.; Moreira, P. N. T.; Araújo, M. C. U.; Anal. Chim. Acta 2003, 486, 143.

28. Nascimento, V. B.; Selva, T. M. G.; Coelho, E. C. S.; Santos, F. P.; Antônio, J. L. S.; Silva, J. R.; Gaião, E. N.; Araújo, M. C. U.; Talanta 2010, 81, 609.

29. Oliveira, S. C. B.; Coelho, E. C. S.; Selva, T. M. G.; Santos, F. P.; Araújo, M. C. U.; Abreu, F. C.; Nascimento, V. B.; Microchem. J. 2006, 82, 220.

30. Almeida, L. F.; Martins, V. L.; Silva, E. C.; Moreira, P. N. T.; Araújo, M. C. U.; J. Braz. Chem. Soc. 2003, 14, 249.

31. da Silva, J. E.; da Silva, F. A.; Pimentel, M. F.; Honorato, R. S.; da Silva, V. L.; Montenegro, B. S. M.; Araújo, A. N.; Talanta 2006, 70, 522.

32. Almeida, L. F.; Vale, M. G. R.; Dessuy, M. B.; Silva, M. M.; Lima, R. S.; Santos, V. B.; Diniz, P. H. D.; Araújo, M. C. U.; Talanta 2007, 73, 906.

33. Visani, V.; Barros, S. R. R. C.; Dantas Filho, H. A.; Almeida, L. F.; Lima, R. A. C.; Fragoso, W. D.; Saldanha, T. C. B.; Araújo, M. C. U.; Ecl. Quím. 2009, 34, 37.

34. Honorato, R. S.; Carneiro, J. M. T.; Zagatto, E. A. G.; Anal. Chim. Acta 2001, 441, 309.

35. Carneiro, J. M. T.; Dias, A. C. B., Zagatto, E. A. G.; Honorato, R. S.; Anal. Chim. Acta 2001, 455, 327.

36. Carneiro, J. M. T.; Honorato, R. S.; Zagatto, E. A. G.; Fresenius J. Anal. Chem. 2000, 368, 496.

37. Souza, M. C.; Martins, V. L.; Almeida, L. F.; Pessoa Neto, O. D.; Gaião, E. N.; Araújo, M. C. U.; Talanta 2010, 82, 1027.

38. Grünhut, M.; Centurión, M. E.; Fragoso, W. D.; Almeida, L. F.; Araújo, M. C. U.; Band, B. S. F.; Talanta 2008, 75, 950.

39. Grünhut, M.; Martins, V. L.; Centurión, M. E.; Araújo, M. C. U.; Band, B. S. F.; Anal. Letter, 2011, 44, 1.

40. Acebal, C. C.; Insausti, M.; Pistonesi, M. F.; Lista, A. G.; Band, B. S. F.; Talanta 2010, 81, 116.

41. Silva, M. J.; Anjos, E. V.; Honorato, R. S.; Pimentel, M. F.; Paim, A. P. S.; Anal. Chim. Acta 2008, 629, 98.

Submitted: October 10, 2010 Published online: February 15, 2011

FAPESP has sponsored the publication of this article. 